\title{
Wittgenstein as a Gricean intentionalist
}

\author{
Elmar Unnsteinsson \\ Postprint. Please cite published Version: \\ British fournal for the History of Philosophy (2016) 24(1): 155-172 \\ doi:10.1080/09608788.2015.1047735
}

\begin{abstract}
According to the dominant view, the later Wittgenstein identified the meaning of an expression with its use in the language and vehemently rejected any kind of mentalism or intentionalism about linguistic meaning. I argue that the dominant view is wrong. The textual evidence, which has either been misunderstood or overlooked, indicates that at least since the Blue Book Wittgenstein thought speaker's intentions determine the contents of linguistic utterances. His remarks on use are only intended to emphasize the heterogeneity of natural language. Taking into account remarks written after he finished the Investigations, I show how Wittgenstein anticipated the basic tenets of Gricean intention-based semantics. These are, in particular, the distinction between 'natural' and 'non-natural' meaning and the distinction between what a speaker means by an utterance and what the expression uttered means in the speaker's natural language. Importantly, Wittgenstein also believed that only the meaning of the speaker determined the content of ambiguous expressions, such as 'bank', on a particular occasion of utterance.
\end{abstract}

\section{Introduction}

My goal in this paper is to argue for two theses:

1. The later Wittgenstein did not endorse the theory that the meaning of a word is its use in the language.

*(凶) elmar.geir@gmail.com

${ }^{*}$ Many thanks to Bill Child, Gunnar Júlíus Guðmundsson, Peter Hacker, Daniel Harris, Lars Hertzberg, Mikael Karlsson, Carlo Penco and Alois Pichler. Thanks also to the audience at the conference 'In Wittgenstein's Footsteps' (Reykjavík, 2012) and the students in my course on Wittgenstein at the University of Iceland that same year. This work was supported by NordForsk [Project no. 070355]. 
2. The later Wittgenstein was an intentionalist about representation and meaning and endorsed the basic tenets of contemporary intention-based semantics.

These are controversial claims. Importantly, (1) is not merely based on the notion that Wittgenstein endorsed a 'no-theory theory' of everything since then (2) would be compromised. The arguments for (1) and (2) are motivated on both exegetical and philosophical grounds. The independent motivation for (1) is roughly that use can only 'determine' meaning in an epistemological sense-knowing the use (or $a$ use) of an expression $e$ is a good way for hearers to figure out or discover the meaning of $e$ on a particular occasion of utterance. A related argument is presented against the idea, often attributed to Wittgenstein, that meaning can be determined by the context of utterance.

For the purposes of this paper, intention-based semantics is the idea that the meanings of linguistic expressions are best explained in terms of certain propositional attitudes, most importantly Gricean communicative intentions. The content, then, of what is said and meant by a speaker who utters a linguistic expression is determined by the intentions with which the speaker utters the expression on an occasion. Specifications of the linguistic meaning of the expression-type itself are, then, just generalisations over the communicative intentions of a group of speakers. Thus expression-type $e$ means, for a group of speakers $G$, what members of $G$ are disposed to intend by uttering $e$. The linguistically encoded meaning of $e$ can also be described as a set of constraints on what a speaker can reasonably intend by its utterance. But it is not my purpose here to go into the finer details of this type of theory.

In $\S 2$, I show that Wittgenstein had an intentionalist view about representation at least since the Blue Book (BB). There, he hints at two distinct arguments against a certain behaviouristic misconception of intentions. I develop these arguments more fully, but they are commonly misunderstood as revealing behaviourist predilections. In $\S 3$, I turn to the so-called use-theory of meaning. I develop three arguments against such theories, the last of which, I argue, is explicitly endorsed by Wittgenstein in the Investigations. The others seem to have worried him but to a lesser extent. Next (§4) I argue that Wittgenstein's early, post-Tractarian ideas about the context-sensitivity of linguistic meaning cannot be accommodated within use-based semantics. Furthermore, I provide textual evidence from Remarks on the Philosophy of Psychology II for interpreting Wittgenstein's mature theory of representation as fully intentionalist and therefore a striking anticipation of modern theories of pragmatics as instigated by Paul Grice (1957). This perspective clearly goes against the current majority view of Wittgenstein scholars.

\footnotetext{
${ }^{1}$ The claim is merely that Wittgenstein endorsed the basics of intentionalism about language and communication. See, for example, Grice (1957); Neale (1992, 2005); Schiffer (1972, 1987, 2003); Wilson and Sperber (2012).
} 


\section{Behaviourism and regress arguments}

There have been serious debates among scholars about whether Wittgenstein was a behaviourist. ${ }^{2}$ I will not address that issue directly. Undeniably, however, Wittgenstein does formulate a kind of methodological behaviourism in the BB. It is common to distinguish reductive behaviourism from eliminative behaviourism. The former refers to the idea that mental phenomena, such as thought, belief and desire, are reducible to physical and behaviouristic phenomena. The latter refers to the idea that, strictly speaking, there is no such thing as folk-psychological thoughts, beliefs or desires: these are simply part of an obsolete theory of the folk, similar to witches, elves and gods. Wittgenstein's methodological behaviourism is not nearly as contentious, although he ultimately does not endorse it.

He points out that theorists are prone to introduce certain specific mental processes in order to explain, for instance, linguistic comprehension. Thus, theorists are tempted to think of linguistic signs simply as inert material objects that acquire some distinctive significance by way of mental acts of interpretation. It is not until sentences are thought, meant, understood and interpreted by human beings that they acquire meaning. Further, these mental acts take place in some 'queer medium' known as the mind. The reason this medium is 'queer' is simply that, by definition, it has effects that no mere material mechanism could have. An alleged example of this is the fact that one can mentally wish for something that will never happen (BB, 3-4).

At this point Wittgenstein proposes a methodological principle bearing the insignia of behaviourism. I reformulate it here in terms that are not quite faithful to his own notorious strictures against generalizations and theories in philosophy:

(P) Any mental process $S$ must be such that $S$ can in principle be replaced by an equivalent physical process $S^{\prime}$ without this having any significant consequences for our overall theory. ${ }^{3}$

The principle is similar to one which Wilfrid Sellars explicitly endorses in Empiricism and the Philosophy of Mind, asserting that, regardless of whether mentalistic concepts reduce to behaviouristic concepts, he will at least ensure that this is true of the concepts that he will employ in his investigation (1997, §56). An example of Wittgenstein's will explain the import of (P). One might believe that in order to understand an utterance of the expression 'red' one must entertain a red image in one's mind. ${ }^{4}$ But then merely looking at a red piece of paper should be able to serve the exact same purpose. Thus, it seems, every imaginative process can easily

\footnotetext{
${ }^{2}$ For example, Bloor (1999); Hacker (1990: 224-253); Luckhardt (1983).

${ }^{3} \mathrm{Cf}$. BB, 4: 'There is one way of avoiding at least partly the occult appearance of the processes of thinking, and it is, to replace in these processes any working of the imagination by acts of looking at real objects.'

${ }^{4}$ Of course, Wittgenstein rejects the claim in question. More on this below.
} 
be replaced by some process of looking at a picture and every process of thinking silently can be replaced by a process of thinking out loud. ${ }^{5}$

Remember, however, that at least one reason why Wittgenstein abandoned the so-called picture theory of meaning, which he endorsed in the Tractatus (TLP), was the realisation that a single picture can be meant in many different ways. Thus one cannot hold that a picture, which is a physical, non-mental object, is intrinsically representational: it must be intended in a specific way (PR, §24). ${ }^{6}$ For instance, a single portrait can be intended to represent different individuals on different occasions. This prompts Wittgenstein's remarks, in the BB, about intentional representation (BB, 32-34). As I see it, he imagines a philosopher who endorses a behaviouristic theory of intention and interpretation: 'Whenever we interpret a symbol in one way or another, the interpretation is a new symbol added to the old one' (BB, 33). The theory is as follows:

(T) Intending $X$ by uttering expression $e$ consists in entertaining some expression $e^{\prime}$ as the interpretation of $e$ (where possibly $e=e^{\prime}$ ).

Wittgenstein suggests, but does not give the details of, two arguments. The first is a regress argument directed at $(\mathrm{T})$ and the second seems to be directed at $(\mathrm{T})$ and (P) at the same time.

Here is my reconstruction of the Regress argument, where 'interpretation' is behaviouristically defined as adding one expression to another-either in the imagination or as a physical process in accord with $(\mathrm{P})$.

\footnotetext{
${ }^{5}$ Wittgenstein's attitude to $(\mathrm{P})$, however, is ambivalent. He even forgets sometimes that $(\mathrm{P})$ can only be a methodological assumption and does not really amount to any kind of description of our ordinary linguistic practices. This occurs at a crucial point in $§ 1$ of the Investigations. Wittgenstein imagines that someone goes shopping with a slip of paper marked 'five red apples.' He then hands the note to the shopkeeper who proceeds to open a drawer marked 'apples,' look up the word 'red' on a colour chart, and count from one to five. For each number he picks up one apple the colour of which fits the colour on the chart. Wittgenstein, surprisingly, claims that it is in this and similar ways that one operates with language'. But this claim is certainly false. Shopkeepers do not use colour charts to find red apples and neither do they go by words written on a drawer. If the drawer marked 'apples' only contained oranges the shopkeeper would not have taken the oranges. One major point of this example, for Wittgenstein, is to illustrate that linguistic comprehension can be described without mentioning the meaning of any expression used. Even if that claim turns out to be true a more realistic example would be needed for it to be established. For some plausible ways of doing this, see Lewis (1969) and Skyrms (1996).

${ }^{6} \mathrm{PR}, \S 24$ reads:
}

How is a picture meant? The intention never resides in the picture itself, since, no matter how the picture is formed, it can always be meant in different ways. But that doesn't mean that the way the picture is meant only emerges when it elicits a certain reaction, for the intention is already expressed in the way I now compare the picture with reality. 


\section{Regress argument}

1. Every expression and every picture can be intended differently on different occasions.

2. If intending $X$ by uttering expression $e$ consists in interpreting $e$ with $e^{\prime}$ (where possibly $e=e^{\prime}$ ) nothing is intended unless $e^{\prime}$ either has intrinsic meaning or is intended some way or other by the speaker.

3. By (1), $e^{\prime}$ does not have intrinsic meaning and must therefore be intended some way or other by the speaker.

4. The speaker's act of intending $e^{\prime}$ will, by (T), consist in interpreting $e^{\prime}$ with $e^{\prime \prime}$ (where possibly $e^{\prime}=e^{\prime \prime}$ ).

5. Thus there is a vicious infinite regress of intentions.

6. Therefore (T) is false.

This argument is valid and sound. Wittgenstein makes his case by example. A pointing gesture or an arrow can be intended in a way that is opposite to the usual interpretation. This intention, according to (T), consists in an added mental gesture pointing in the opposite direction, which leads to a vicious regress. Thus, Wittgenstein writes: 'And this process of meaning, of whatever kind it may be, can be represented by another arrow (pointing in the same or the opposite sense to the first)' (BB, 33).

Notice that the Regress argument does not tell against principle $(\mathrm{P})$. The argument could not establish a vicious regress with respect to $(\mathrm{P})$, as $(\mathrm{P})$ only involves the idea that a mental process $S$ must in principle be replaceable by an equivalent physical process $S^{\prime}$. And even if every such replacement can in turn be replaced ad infinitum ordinary people are not actually required to replace any process by any other process. $(\mathrm{P})$ only places a constraint on the vocabulary employed by the theorist in describing ordinary agents. If ordinary speakers who intend $X$ by uttering $e$ are not required to make any mental replacements of this kind then, $a$ fortiori, they do not need to make an infinite number of them. It is clear, however, that the example Wittgenstein uses to illustrate $(\mathrm{T})$ does invite the charge of a possible vicious regress. The theory that intending red by uttering 'red' consists in imagining a further symbol, say a red patch, clearly leads to a vicious regress as any imagined symbol must also be intended in some way. One must understand that the red image is indeed red and intend it as a representation of red.

Second, Wittgenstein hints at what I will call the No replacement argument. He imagines that we might just stipulate the level at which the intention itself resides and, so, avert the infinite regress. ${ }^{7}$ Suppose then that the intention-symbol is only

\footnotetext{
${ }^{7} \mathrm{BB}, 34$ : 'But adopt whatever model or scheme you may, it will have a bottom level, and there will be no such thing as an interpretation of that.'
} 
one step below the linguistic symbol which is uttered. Wittgenstein asserts that the replacement expression $e^{\prime}$ would have to be equivalent to the intention with which the person makes her utterance: 'Now I assume that you take the meaning to be a process accompanying the saying, and that it is translatable into, and so far equivalent to, a further sign' (BB, 34). But he has also made the assumption that any expression can be intended in different ways on different occasions. We might add that although intentions themselves can indeed be intended in different ways, for example, I can either intend or not intend to make you aware of some intention of mine, that is clearly different from having a single expression and intending different things by it on different occasions. Thus, Wittgenstein concludes, expressions cannot be equivalent to intentions and no symbol can replace an intention.

There is, however, a sense in which 'replacement' is sometimes acceptable. This is in those special cases when a speaker intends $X$ by uttering $e$ and $X$ happens to be some further linguistic expression. Consider the following. One might intend to communicate that it's raining in New York by uttering (1) while in New York (cf. Perry 1986).

(1) It's raining.

But it does not follow that the speaker thereby also intended to communicate sentence (2) by uttering (1).

(2) It's raining in New York.

Yet she might very well have intended this very sentence by some other utterance. Thus, if sentence (2) is the speaker's favourite sentence, she could have said 'My favourite sentence is true' and thereby this very sentence would be (part of) her intention. The relation between (1) and (2) is best described by saying that both can be uttered to express (roughly) the same proposition on different occasions. But it does not follow that one expression is intended while the other is uttered. This point seems to be supported by Wittgenstein's related discussion in PI §§19-20 (cf. Goldfarb 1983).

In terms of Wittgenstein's example in the $\mathrm{BB}$, when the pointing gesture is intended in the usual way the gesture is not intended to refer to another pointing gesture that is equivalent to the one actually performed. Still, such a feat might be accomplished by referring to, say, one's favourite sentence-that is, if the uttered sentence is identical to the favourite sentence. However, the intention can be represented by some additional expression or gesture and thus, to that extent, satisfies (P). My intention to communicate that it's raining in New York by uttering (1) may be represented by (2) without the intention thereby being 'equivalent' to (2). This conclusion seems trivial since my intention can also be 'represented' in a different language from the language actually spoken. 
There are at least two ways to go from here. Either one accepts eliminative behaviourism or just rejects $(\mathrm{P})$. Some may think that Wittgenstein is an eliminativist about intentions but that is clearly false. He thinks the two arguments above reveal something important about mentalistic concepts such intention and understanding, but it is not that these words refer to nothing (cf. PI, §304). Thus, he rejects $(\mathrm{P})$, but he might still accept some weaker analogue. Intending something by an expression just cannot be equivalent to a further expression that occurs in the imagination 'while' one has an intention. My occurrent thoughts are not, as such, determinative of my intention in speaking. ${ }^{8}$ More specifically, such thoughts do not determine the meaning of an expression on the occasion of utterance. Arguing against such a theory is one of Wittgenstein's major concerns in the Investigations. And the negative point remains true even if a further symbol can represent the intention in some other sense. This lends support to Wittgenstein's claim in Zettel that intention is 'neither an emotion, a mood, nor yet a sensation or image. It is not a state of consciousness. It does not have genuine duration' ( $\mathrm{Z}, \S 45)$.

More generally, then, Wittgenstein can plausibly be construed as arguing that intentions belong in the larger category of nonepisodic mental states. A typical example of such a state is standing belief. You are probably not actively entertaining the belief that houses exist, but you would assent to it upon being asked. This belief is a nonepisodic standing belief of yours. It is plausible to claim that expecting, wanting, knowing and intending are similarly nonepisodic in nature. Or, at least, that they are sometimes mental episodes but sometimes not. But then intention does not necessarily consist in conscious mental episodes. In his 'middle' or 'transition' period-roughly 1929-1933-Wittgenstein writes:

By 'intention' I mean here what uses a sign in a thought. The intention seems to interpret, to give the final interpretation; which is not a further sign or picture, but something else, the thing that cannot be further interpreted. (PG, 145; Z, §231)

It seems clear, then, that Wittgenstein was an intentionalist about representation as early as the $\mathrm{BB}$, where he writes that ' $[\mathrm{a}] \mathrm{n}$ obvious, and correct, answer to the question "What makes a portrait the portrait of so-and-so"? is that it is the intention' (BB, 32, emphasis in original; cf. PG, 102; PPF, §§17-18; LW I, §318). By analogy, I think, he should have said that only the intention of the speaker $S$ makes it the

\footnotetext{
${ }^{8}$ I use 'as such' to hedge the claim. Here is how I would describe the case more fully (this is not what Wittgenstein would say): the fact that some thought $T$ is occurrent in my mind while I utter $e$ intending $X$ does not imply that $T$ determines my intention. But this is simply because one can have many (episodic or nonepisodic) thoughts at roughly the same time. Thus when I utter 'This is blue' while a green image crosses my mind, the green image does not make it the case that I really meant this is green rather than this is blue. But it does not follow that no conscious thought of mine determined the content of my intention. One can insist that I was also having an occurrent thought about blue-it is just that this thought did not consist in a mental representation as of a blue image.
} 
case that by uttering, say, 'she' $S$ means one contextually salient woman rather than another (cf. PI, §§661-663). And if the intention is unclear to the audience, the speaker can be asked to clarify her meaning. The 'use' and the 'context' of use are merely of epistemological value: they serve as tools for the hearer to discover what the speaker intends.

\section{Meaning and use}

Let us turn to use-based semantics. When Wittgenstein writes, in PI $§ 43$, that for a large class of cases the meaning of a word can be explained by describing its use, this should only be taken as a reminder of the variety of linguistic practices the countenancing of which the Augustinian picture of language discourages. It is not reasonable to argue that Wittgenstein intends the remark as a theory of the semantics of natural language. Many theorists, however, have construed it in such a manner. There are three main reasons for not doing this.

First, an explanation of a meaning can refer to almost anything, depending on the epistemic state of the one in need of an explanation. ${ }^{9}$ Generally, the fact in virtue of which $p$ is the case does not have to be mentioned when one explains to someone that $p$ is the case. Therefore, the alleged fact that the use of expression $e$ is often cited in explanations of the meaning of $e$ does not show that use is that in virtue of which $e$ has its meaning. To illustrate, the fact in virtue of which Paris is the capital of France is usually not cited when the fact that Paris is the capital of France is explained to the uninformed. The former refers to a complex historical event while the latter can be, for example, the act of pointing to Paris on a map.

Second, the individuation of uses is a complete mess. ${ }^{10}$ Take neologisms. Until a neologism is first uttered it does not have a use. Thus when one explains a neologism one cannot be explaining its (actual) use in the language. A use-theorist will reply that one is explaining how one will use the new term. But the problem is exacerbated when we move to whole sentences. As Chomsky pointed out, most sentences of English will never be used. This follows from the fact that the sentences are infinitely many, because of recursion. And how can use then determine

\footnotetext{
${ }^{9}$ This does not go against Wittgenstein's injunction that the meaning will be what the explanation of the meaning explains-for that is a mere platitude $(\mathrm{BB}, 1)$.

${ }^{10}$ It is not noted often enough that Wittgenstein deleted a few sentences from PI $§ 41$ where he aired a similar worry:
}

Vielleicht wäre es richtiger zu sagen: Eine Bedeutung eines Wortes ist eine Art seines Gebrauchs in der Sprache. Hier ist die Frage offen gelassen, was wir einen einheitlichen Gebrauch, und was einen doppelten nennen werden. Ich glaube es wird sich zeigen, daß sich dafür keine scharfgeschnittenen Regeln angeben lassen. (Cf. Baker and Hacker 2005b: 121) 
the meaning of these sentences? ${ }^{11}$ These remarks should remind us of how unclear the notion really is: Which use are we describing? The overall past use of the term, with which no finite mind could be familiar? One's personal use of the term? The use to which one is putting the term at some particular occasion? The uses one remembers? The future use of the term? The 'correct' use? The list is endless.

These worries are mentioned here to give some idea of the difficulties involved in the picture of meaning as use. Of course there are numerous authors who have developed this idea further and tried to give answers to the most pressing questions. ${ }^{12}$ Here, however, I want to argue that the major problem Wittgenstein saw in use-based semantics was a very simple one, although orthodox interpretations underestimate the extent to which it worried him (e.g. Baker and Hacker 2005a: chap. 17).

In PI §138, Wittgenstein writes that 'we understand the meaning of a word when we hear or say it; we grasp the meaning at a stroke, and what we grasp in this way is surely something different from the 'use' which is extended in time!' This gives rise to a paradox. If the meaning of $e$ is the use of $e$ then understanding the meaning of $e$ is identical to understanding its use. But since speakers and hearers apparently understand meanings immediately they must, according to the theory, understand 'at a stroke' all the ways in which an expression should be or has been used, depending on the details of the theory one pursues. Sellars' inferential-role semantics, for example, faces the exact same problem: 'the conceptual meaning of a descriptive term is constituted by what can be inferred from it in accordance with the logical and extra-logical rules of inference of the language (conceptual frame) to which it belongs' (1953: 136). Since the use or role of the expression includes extra-logical inferences, the information one must possess in order to understand a simple term amounts to a vast encyclopaedia-like entry. For instance, 'This is a horse' allows the extra-logical inference 'This is an animal' and many more. But how could one grasp such vast amounts of information 'at a stroke' as Wittgenstein puts it?

In PI §§138-139 and RFM §130, Wittgenstein clearly commits himself to the idea that people 'grasp the whole use of a word' at a stroke. His major concern, as John McDowell (1980: 223) puts it in a closely related context, is a certain seductive misconception of this innocent phrase. The misconception says that at-a-stroke understanding is an episodic mental state which determines the correct usage of the expression. This kind of mental state is a philosopher's myth, on Wittgenstein's account. To illustrate, he uses the example of 'cube' and claims that having a mental image of a cube cannot be a state from which correct use of the expression 'cube' emanates: having such an image appear before one's mind's eye as it were is not sufficient for understanding or correctly using the expression (PI, §139).

Wittgenstein argues that grasping the meaning of an expression at a stroke

\footnotetext{
${ }^{11}$ For discussion, see Lewis (1992) and Schiffer (1993).

${ }^{12} \mathrm{Cf}$. Horwich (1998: chap. 3 and citations therein).
} 
does not guarantee that one's future application of that expression will be correct. Sometimes we make mistakes, and we also need to make room for entirely novel yet legitimate understandings of expressions. Consider his example of an instructor who teaches a student the mathematical rule 'add 2' (PI, §§185-188). The instructor gives examples and tells the student to go on in the same way. The student may have a moment of immediate understanding and start writing the series ' $2,4,6$, $8 \ldots$ ' until he reaches 1,000 . Suppose that he then writes ' $1004,1008,1012 \ldots$ '. Certainly, this kind of situation is exceptionally improbable. Yet we seem justified in thinking that the instructor actually meant that the student was to write ' 1002 , $1004,1006 \ldots$ '..' and not ' $1004,1008,1012 \ldots$... But does this imply that she must have thought of the former series and not of the latter? Well, both series might have crossed her mind; but surely that would be irrelevant. Clearly, the instructor did not think the whole series through, because it is infinite, but she undeniably meant the whole infinite series. How can this be? Did her mind 'enter hyperspace' and catch a glimpse of every step in the series from there? No. But this goes to show that intending and meaning are very different from thinking, that is, they are, again, nonepisodic mental states, rather than mental 'activities' (PI, §693). As Wittgenstein stresses, he is not denying the idea that understanding is some kind of state of the person. He is denying the notion that such a state can somehow contain all future moves in advance.

The substantial point here is as follows. The problem of understanding at a stroke is only a problem for those who do not distinguish clearly between what a speaker means by an utterance on an occasion and what the sentence uttered means in the speaker's language. The distinction is a fundamental tenet of intentionalism and some interpreters have lamented discreetly that it evaded Wittgenstein's genius (e.g. Baker and Hacker 2005a: 73). If my argument in this paper is right, however, the distinction was not completely lost on him. One point of the rule-following considerations is to show that there is a type of understanding without interpretation. And this is the understanding of what the speaker means independent of what rules or conventions govern the expressions uttered-for such things cannot be understood at a stroke. For obvious reasons, Wittgenstein did not offer the distinction in the form of an explanatory theory, but, as I argue further below, it still played a foundational role in his overall picture of linguistic meaning.

\section{The psychology of meaning}

Anyone who reads Wittgenstein carefully will notice a tension between two types of remarks he makes about linguistic meaning. A nice illustration can be found in the Brown Book (BB, 114):

[W]hen we ask a doctor 'Can the patient walk?', we shall sometimes be ready to substitute for this 'Is his leg healed?'-'Can he speak?' 
under circumstances means 'Is his throat all right?', under others (e.g., if he is a small child) it means 'Has he learned to speak?'

Wittgenstein makes a similar point about the 'circumstances' of an utterance in many other places. But it is difficult to see how a use-based theory of meaning can accommodate this point. More specifically, if individuating the use or meaning of expression $e$ depends on something further, that is, 'circumstances' or 'contexts', it seems like the use is not doing any important theoretical work anymore. How many uses does the sentence (a) 'Can he speak?' have? Wittgenstein's list is obviously not exhaustive. It could also be substituted for (b) 'Is this robot a speaking robot?' or (c) 'Has he stopped grieving and started talking to his family?' But it would be preposterous to say that (a), (b) and (c) all have the same use. And if one insists that they have the same use, but only in this particular context, then one must explain how the context does this such that 'use' remains the fundamental explanatory notion.

This is something, or so I suggest, Wittgenstein was sensitive to when he claims that meanings can be determined by contexts-especially when he was concerned with the distinction between 'ordinary' and 'philosophical' contexts (PI, §116). The claim, however, that contexts are determinative raises more questions than it answers. And this fact has been explored in quite some detail in the contemporary literature on contextualism in the philosophy of language. Without going into detail, one question is the following: in what sense can context 'determine' the meaning of an expression? On reflection it appears that context cannot be constitutive of or even partly constitutive of the meaning of an expression. The context can only determine meaning in the epistemological sense that the hearer can use the context in order to figure out what the meaning is or what the speaker intends on this occasion (cf. Bach 2005; Neale 2005). This is clear in the cases imagined in (a), (b) and (c) above.

The only fact that can ground meaning in the sense of constituting it is the intention of the speaker. The meaning of 'Can he speak?' on a particular occasion is determined by the intention of the speaker when she makes this utterance. The context cannot assume control over the speaker and determine her meaning for her. Consider, for example, slips of the tongue. If I intend to refer to Gunnar but accidentally utter 'Mike' my intention is not retroactively altered. Of course, I am responsible for making the error in performance and this can have legal consequences and whatnot, but my intention itself cannot change on account of the slip. Furthermore, in a given context the hearer can easily be aware that the speaker meant to refer to Gunnar although he uttered 'Mike' and not 'Gunnar'.

If one considers Wittgenstein's notes published as Remarks on the Philosophy of Psychology II (RPP II), he ends up making essentially this point. And the last two remarks in the Investigations (\$§692-693) point in the same direction: we are misled by superficial similarities of grammatical form and imagine that 'meaning' is similar to 'thinking'. But when one means and intends, say, that the student is 
to write ' 4302 ' after ' 4300 '-although one merely gave expression to the general rule 'add 2'-this meaning cannot consist in having thought of this particular step. Or any particular step. But the meaning of the utterance is still constituted by the speaker's nonepisodic intention in producing it. RPP II is from a typescript dictated in late 1948, based on manuscripts written between November 1947 and August 1948. It is generally agreed that the Investigations-at least what was formerly known as 'Part I'-had acquired more or less its final form by June 1945. Here is the first paragraph of RPP II §176:

If I say that I am using the words 'I'm in pain', 'I'm looking for', etc. etc. as a piece of information, not as a natural sound, [Footnote: Var. 'not as a natural sound, but rather to communicate something, as a report'.] then this characterizes my intention. For instance, I might want somebody to react to this in a certain way.

Wittgenstein is suggesting, it seems, a distinction between using expressions as (i) natural sounds and to (ii) communicate information. Call the latter the 'communicative' use of an expression. Describing the use in this way is to characterise one's intention, apparently the speaker's intention to induce a specific reaction in the audience. 'Natural sounds', however, are a piece of instinctive verbal behaviour not prompted by the speaker's expectation that it will have specific effects on some person. Wittgenstein clearly assumes that a sentence like 'I'm in pain' can be uttered, presumably on different occasions, both as a natural sound and to communicate information. It is not to my purpose to discuss his controversial notion of 'avowal' or Äußerung or whether 'I'm in pain' can be an example of such utterances (see e.g. Bar-On 2004; Finkelstein 2003; Moran 2001). In PI §244, he writes that it is possible that words-words referring to sensations in particular-are 'connected with the primitive, natural, expression of sensation and used in their place'. Refinements aside, however, it is at least reasonable to think that some utterance-types, crying and moaning for instance, are closer to being 'natural sounds' than 'pieces of information'.

These ideas bear a startling resemblance to the basic insights of the Gricean programme in contemporary philosophy of language. In Grice's original definition of 'non-natural meaning' (i.e. meaning ${ }_{\mathrm{NN}}$ ) he writes: " $A$ meant $_{\mathrm{NN}}$ something by $x$ " is (roughly) equivalent to " $A$ intended the utterance of $x$ to produce some effect in an audience by means of a recognition of this intention"' (Grice 1957: 385). This definition spawned a vast literature on 'communicative intentions' which are characterized, as Wittgenstein does above, in terms of the speaker wanting to produce some cognitive effect in the hearer (e.g. Neale 1992; Wilson and Sperber 2012). Consequently, contemporary Gricean pragmatics and speech-act theory is much closer to Wittgenstein's later philosophy of language than often is assumed (cf. Carruthers 1996; Hacker 2010; Hanfling 2000). If my exegesis is accurate this can already be gleaned from Wittgenstein's rejection of use-theoretic semantics in 
the Investigations. Furthermore, Grice's 1982 paper, 'Meaning Revisited' is largely devoted to spelling out how an instinctive cry-occurring as a mere natural soundcan evolve into more sophisticated forms of communication along with a creature's increased intelligence and memory (see Scott-Phillips 2015, §4.7 for discussion).

Two more remarks in RPP II are of particular interest here. First, Wittgenstein writes:

What is important is that we intend something when we utter a word. For example, I say 'Bank!' and want thereby to remind someone to go to the bank, and intend 'bank' in the one meaning and not in the other.-But intention is no experience. (\$242)

This is evidence that the ground of a contextual or circumstantial difference in meaning is the speaker's intention; the intention is 'what is important'. The ambiguity of 'bank' provides a perfect example for illustration, as contemporary Griceans are prone to point out. Humans are intention-recognition machines and are not much concerned with the 'literal' or 'minimal' meaning of sentences-if there is such a thing (cf. PI, §648, also Sperber and Wilson 2005). ${ }^{13}$

Second, in the next paragraph RPP II \$176 Wittgenstein rightly acknowledges that he still owes 'an explanation of the concept of intention' but he provides a starting point for an explanation when he later remarks: 'Intention can be called a mental disposition' (RPP II, §178). But it is a very special kind of disposition in that one does not perceive the disposition within oneself as a matter of experience. Thus it is, Wittgenstein thinks, quite different from having an inclination towards jealousy-which one may recognize from repeated instances of jealousy (RPP II, §178). The suggestion does, however, make sense of his insistence that intention cannot be any type of experience and thus it cannot be equivalent to a symbol used in thought. It can only be what uses a sign in thought and gives the final interpretation (cf. §2 above).

\footnotetext{
${ }^{13}$ In RPP II $§ 245$, Wittgenstein writes:
}

That it is possible after all to utter the word in isolation, far removed from any intention, 'now with one meaning, now with another', is a phenomenon which has no bearing on the nature of meaning; as if one could say, 'Look, you can do this with a meaning too'.-No more than one could say: 'Look at all the things you can do with an apple: you can eat it, see it, desire it, try to form an image of it.' No more than it is characteristic of the concept 'needle' and 'soul' that we can ask how many souls can fit on the point of a needle.-We're dealing here, so to speak, with an outgrowth of the concept.

I understand this as saying that the 'core' of the concept of meaning is intentional. What is important is that one intends something by uttering an expression and that the concept is thereby expressed. One does not latch on to the concept itself by exploring simply what can be done with it regardless of the speaker's actual intention. 
Here is how I understand Wittgenstein's suggestion. The fact that 'bank' means 'financial institution' rather than 'river bank' on some occasion of utterance is explained by the speaker's intention in uttering, or in using, the expression. The intention itself is grounded in a mental disposition, that is, the speaker has a disposition to utter the expression with this particular communicative intention. She may also have a disposition to utter the same expression with another intention, for example, the intention to refer to a river bank. The speaker also believes, in the normal case, that the hearer has a related mental disposition, enabling the hearer to interpret the expression correctly on a particular occasion, using contextual cues and background information. If the speaker did not have this belief she would not be able to even form the intention in question. The reason for this is that Griceans, like Wittgenstein, think there are doxastic constraints on intention formation. The general idea is simply that one cannot intend to $V$ if one in fact thinks that it is highly improbable that one will be able to $V$. And this is why, as in Wittgenstein's example, one is not able to utter 'bububu' and mean 'If it doesn't rain, I shall go for a walk' (PI, boxed remark between $\S 35$ and §36). Unless the context is a very odd one, the speaker will not believe that it is possible to utter 'bububu' with that communicative intention. As Wittgenstein also stresses (PI, §337), intentions are embedded in a setting, in human customs and institutions:

If the technique of the game of chess did not exist, I could not intend to play a game of chess. To the extent that I do intend the construction of an English sentence in advance, that is made possible by the fact that I can speak English. ${ }^{14}$

Thus the so-called Humpty Dumpty objection does not tell against intention-based semantics: one cannot intend to mean whatever by whatever whenever. ${ }^{15}$

\section{Conclusion: The immediacy of understanding}

What people understand immediately or at a stroke is the intention with which a symbol is produced. The intention is not identical or equivalent to any linguistic expression and, a fortiori, not equivalent to the use of an expression. Of course there are different ways to go here and difficulties raised by each option. This is no place to weigh in on that debate. The general idea, however, is that a hearer $H$ understands immediately the speaker's intention to produce a specific response in $H$. The response can be, for example, to form the belief that it's raining in Reykjavik. English speakers, then, are disposed to produce this response by uttering the

\footnotetext{
${ }^{14}$ Glock (1996: 182), interprets PI $§ \S 614-616$ along these lines also-but this is quite dubious. For discussion see, for example, Donnellan (1968); Bratman (1984); Mele (2001).

${ }^{15}$ For the Humpty Dumpty objection, see Donnellan (1968); Unnsteinsson (2014).
} 
expression 'It's raining' while they are in Reykjavík and believe that the hearer is aware of this.

The connection between rule-following and linguistic understanding in Wittgenstein's philosophy has been overemphasized by commentators. The ability to follow rules is merely analogous to the ability to understand linguistic expressions and does not explain it. ${ }^{16}$ Also, rule-following should be construed in terms of learning rather than understanding. In uttering a linguistic expression $e$, a speaker usually does not intend to teach the audience how to use $e$. This only happens in special cases and there is even little reason to suppose that this is how children learn their first language. Furthermore, learning how to use an expression is not something that happens 'at a stroke'-although this is surely conceivable. In ordinary communication speakers utter expressions $e$ such that they have a prior expectation that the audience is familiar with $e$ and can thus use the fact that $e$ was uttered as evidence for the speaker's intention. There is no need to suppose that the hearer must 'understand' the whole use of $e$, at a stroke or otherwise, in order to infer the intention of the speaker. Minimally, we can assume that the hearer may need to process stored information about what speakers in some group are generally disposed to communicate by uttering $e$ in particular contexts.

\section{Bibliography}

Bach, K., 2005. "Context ex machina." Z. G. Szabó (ed.), Semantics versus pragmatics, Clarendon, pp. 15-44.

Baker, G. P. \& Hacker, P. M. S., 2005a. Wittgenstein: Understanding and meaning. Vol. 1 of an Analytical commentary on the Philosophical investigations. Part I: Essays. Blackwell Publishing. Second, extensively revised edition (by P. M. S. Hacker). (Orig. pub. 1980.).

,$--- 2005 b$. Wittgenstein: Understanding and meaning. Vol. 1 of an Analytical commentary on the Philosophical investigations. Part II: Exegesis $\$$ 1-184. Blackwell Publishing. Second, extensively revised edition (by P. M. S. Hacker). (Orig. pub. 1980.).

Bar-On, D., 2004. Speaking my mind: Expression and self-knowledge. Clarendon Press.

Bloor, D., 1999. "Wittgenstein's behaviorism.” Handbook of behaviorism, Academic Press, pp. 329-361.

Bratman, M., 1984. “Two faces of intention.” The Philosophical Review, 93(3):375405.

Carruthers, P., 1996. Language, thought and consciousness. CUP.

Donnellan, K., 1968. "Putting Humpty Dumpty together again." The Philosophical Review, 77(2):203-215. Repr. in Donnellan (2012), pp. 31-48.

\footnotetext{
${ }^{16}$ Here I am in complete agreement with Glüer and Wikforss (2010).
} 
---, 2012. Essays on reference, language, and mind. OUP.

Finkelstein, D. H., 2003. Expression and the inner. HUP.

Glock, H.-J., 1996. A Wittgenstein dictionary. Blackwell.

Glüer, K. \& A. Wikforss, 2010. "Es braucth die Regel nicht: Wittgenstein on rules and meaning." The later wittgenstein on language, Palgrave Macmillan, pp. 148166.

Goldfarb, W. D., 1983. "I want you to bring me a slab: Remarks on the opening sections of the Philosophical Investigations." Synthese, 56(3):265-282.

Grice, P., 1957. "Meaning." The Philosophical Review, 66(3):377-388. Repr. in Grice (1989), pp. 213-223.

---, 1982. "Meaning revisited." N. Smith (ed.), Mutual knowledge, Academic Press, pp. 223-243. Repr. in Grice (1989), pp. 283-303.

-- - 1989. Studies in the way of words. HUP.

Hacker, P. M. S., 1990. Wittgenstein: Meaning and mind. Vol. 3 of an Analytical commentary on the Philosophical investigations. Basil Blackwell.

-- , 2010. "Meaning and use." The later wittgenstein on language, Palgrave Macmillan, pp. 26-44.

Hanfling, O., 2000. Philosophy and ordinary language: The bent and genius of our tongue. Routledge.

Horwich, P., 1998. Meaning. OUP.

Lewis, D., 1969. Convention: A philosophical study. HUP.

-- - 1992. "Meaning without use: Reply to Hawthorne." Australasian fournal of Philosophy, 70(1):106-110.

Luckhardt, C. G., 1983. "Wittgenstein and behaviorism." Synthese, 56(3):319-338.

McDowell, J. H., 1980. "Meaning, communication, and knowledge." Philosophical subjects: Essays presented to P. F. Strawson, Clarendon Press, pp. 117-39. Repr. in McDowell (1998), pp. 29-50.

---, 1998. Meaning, knowledge, and reality. HUP.

Mele, A., 2001. "Acting intentionally: Probing folk notions.” B. Malle, L. Moses, \&

D. Baldwin (eds.), Intentions and intentionality: Foundations of social cognition, MIT Press, pp. 27-43.

Moran, R., 2001. Authority and estrangement: Essays on self-knowledge. Princeton University Press.

Neale, S., 1992. "Paul Grice and the philosophy of language." Linguistics and Philosophy, 15(5):509-559.

---, 2005. "Pragmatism and binding." Z. G. Szabó (ed.), Semantics versus pragmatics, Clarendon, pp. 165-285.

Perry, J., 1986. "Thought without representation." Proceedings of the Aristotelian Society, (Supp. vol.) 60:137-152. Repr. in Perry (2000), pp. 171-188.

,--- 2000 . The problem of the essential indexical and other essays: Expanded edition. CSLI Publications.

Schiffer, S., 1972. Meaning. OUP. 
,--- 1987. Remnants of meaning. CUP.

---, 1993. “Actual-language relations.” Philosophical Perspectives, 7:231-258.

---, 2003. The things we mean. Clarendon.

Scott-Phillips, T., 2015. Speaking our minds: Why human communication is different, and how language evolved to make it special. Palgrave Macmillan.

Sellars, W., 1953. "Is there a synthetic a priori?" Philosophy of Science, 20(2):121-138.

---, 1997. Empiricism and the philosophy of mind (with an introduction by Richard Rorty and a study guide by Robert Brandom). HUP.

Skyrms, B., 1996. Evolution of the social contract. CUP.

Sperber, D. \& Wilson, D., 2005. "Pragmatics." F. Jackson \& M. Smith (eds.), The Oxford handbook of contemporary philosophy, OUP, pp. 468-501. Repr. in Wilson \& Sperber (2012), pp. 1-27.

Unnsteinsson, E. G., 2014. "Compositionality and sandbag semantics." Synthese, 191(14):3329-3350.

Wilson, D. \& Sperber, D., 2012. Meaning and relevance. CUP.

Wittgenstein, L., 1953a. Philosophical investigations (PI). Wiley-Blackwell, 4 edn. Translated by G. E. M. Anscombe, P. M. S. Hacker, J. Schulte (2009).

---, 1953b. Philosophy of psychology - A fragment (PPF). Blackwell. In PI.

,--- 1958 . The blue and brown books (BB). Blackwell. Reference to page numbers.

---, 1961. Tractatus logico-philosophicus (TLP). Routledge \& Kegan Paul. Translated by D. F. Pears and B. F. McGuinness; first published in 1921.

---, 1967. Zettel (Z). Blackwell. Edited by G. E. M. Anscombe and G. H. von Wright, translated by G. E. M. Anscombe.

---, 1974. Philosophical grammar (PG). Blackwell. Edited by R. Rhees, translated by A. J. P. Kenny.

---, 1975. Philosophical remarks PR). Blackwell. Edited by R. Rhees, translated by R. Hargreaves and R. White.

---, 1978. Remarks on the foundations of mathematics (RFM). Blackwell. Edited by G. H. von Wright, R. Rhees and G. E. M. Anscombe, translated by G. E. M. Anscombe, rev. edn.

---, 1980. Remarks on the philosophy of psychology, vol. II (RPP II). Blackwell. Edited by G. H. von Wright and H. Nyman, translated by C. G. Luckhardt and M. A. E. Aue.

---, 1982. Last writings on the philosophy of psychology, vol. I (LW I). Blackwell. Edited by G. H. von Wright, H. Nyman, Translated by C. G. Luckhardt, M. A. E. Aue. 